Research Paper

\title{
Enhanced tumor growth inhibition by mesenchymal stem cells derived from iPSCs with targeted integration of interleukin24 into rDNA loci
}

\author{
Bo Liu ${ }^{1}$, Fei Chen ${ }^{1}$, Yong Wu ${ }^{1}$, Xiaolin Wang ${ }^{1}$, Mai Feng ${ }^{1}$, Zhuo Li $^{1}$, Miaojin Zhou ${ }^{1}$, \\ Yanchi Wang ${ }^{1}$, Lingqian $\mathbf{W u}^{1}$, Xionghao Liu ${ }^{1}$ and Desheng Liang ${ }^{1}$ \\ ${ }^{1}$ The State Key Laboratory of Medical Genetics and School of Life Sciences, Central South University, Changsha, China \\ Correspondence to: Desheng Liang, email: liangdesheng@sklmg.edu.cn \\ Xionghao Liv, email: liuxionghao@sklmg.edu.cn
}

Keywords: rDNA locus, gene targeting, MSCs derived from iPSCs, IL24, anti-tumor

Received: August 17, $2016 \quad$ Accepted: March 13, $2017 \quad$ Published: March 28, 2017

Copyright: Liu et al. This is an open-access article distributed under the terms of the Creative Commons Attribution License 3.0 (CC BY 3.0), which permits unrestricted use, distribution, and reproduction in any medium, provided the original author and source are credited.

\section{ABSTRACT}

Induced pluripotent stem cells (iPSCs) are a promising source of mesenchymal stem cells (MSCs) for clinical applications. In this study, we transformed human iPSCs using a non-viral vector carrying the IL24 transgene pHrn-IL24. PCR and southern blotting confirmed IL24 integration into the rDNA loci in four of 68 iPSC clones. We then differentiated a high expressing IL24-iPSC clone into MSCs (IL24-iMSCs) that showed higher expression of IL24 in culture supernatants and in cell lysates than control iMSCs. IL24iMSCs efficiently differentiated into osteoblasts, chondrocytes and adipocytes. Functionally, IL24-iMSCs induced in vitro apoptosis in B16-F10 melanoma cells more efficiently than control iMSCs when co-cultured in Transwell assays. In vivo tumor xenograft studies in mice demonstrated that IL24-iMSCs inhibited melanoma growth more than control iMSCs did. Immunofluorescence and histochemical analysis showed larger necrotic areas and cell nuclear aggregation in tumors with IL24-iMSCs than control iMSCs, indicating that IL24-iMSCs inhibited tumor growth by inducing apoptosis. These findings demonstrate efficient transformation of iPSCs through gene targeting with non-viral vectors into a rDNA locus. The ability of these genetically modified MSCs to inhibit in vivo melanoma growth is suggestive of the clinical potential of autologous cell therapy in cancer.

\section{INTRODUCTION}

Human mesenchymal stem cells (MSCs) are adherent adult stem cells with an ability to differentiate into various mesenchymal cell types like osteoblasts, adipocytes, and chondrocytes [1]. MSCs are also involved in immunosuppression and migrate to sites of inflammation and tumors [2-5]. Many studies have shown that MSCs can be used as cellular vehicles to carry antitumor agents to tumor sites and inhibit tumor growth in animal models [6-10]. However, loss of differentiation potential and decline of proliferation during ex vivo expansion has limited their clinical application $[11,12]$. Recently, human induced pluripotent stem cells (iPSCs) have become promising alternate source of MSCs that can be used for autologous cellular therapy in cancer $[13,14]$.
While most studies have used viral vectors to modify MSCs, it is preferable to use non-viral methods to engineer therapeutic cells for safety considerations. However, their lack of integration into host genome has prevented long term expression that is necessary for clinical applications. However, the ribosomal DNA (rDNA) locus that consists of nearly 400 copies of the 45S pre-RNA ( $r R N A)$ gene clustered on the short arms of all five acrocentric chromosomes 13, 14, 15, 21, and 22 with high transcriptional activity has been explores as a candidate site for transgene integration and long term expression [15]. Previously we successfully targeted a non-viral vector into the rDNA locus of different human cell types including hepatocyte cell lines, MSCs and embryonic stem cells (ESCs) and demonstrated efficient expression of transgenes [16-18]. 
Interleukin 24 (IL24), also called melanoma differentiation associated gene $7(M D A 7)$, is a unique cytokine and tumor suppressor gene that belongs to the IL10 cytokine family [19]. Human IL24 is a single copy gene that is located on chromosome 1 (q32.2-q41) and encodes a protein of 206 amino acids [20]. It has demonstrated significant anti-tumor activity in preclinical animal models [21-28]. Overexpression of IL24 selectively inhibits the growth of melanoma cells and induces apoptosis [29, 30].

In the present study, we transformed human iPSCs by targeting a non-viral vector ( $\mathrm{pHrn}$ ) containing IL24 into the rDNA locus using transcription activator-like effector nickase (TALENickase). Further, we differentiated the transformed iPSCs into iMSCs and characterized their anti-melanoma properties, both in vitro and in vivo.

\section{RESULTS}

\section{Construction of pHrn-IL24}

We constructed an optimized rDNA targeting plasmid, pHrn-IL24 (Figure 1A), which contained a promoter-less neomycin resistance cassette and a cytomegalovirus (CMV) enhancer driven human IL24 ORF cassette for integration into the $45 \mathrm{~S}$ pre-RNA gene [16]. The two cassettes were flanked by a short 5' left homologous arm (935 bp) and a short 3' right homologous arm (596 bp). The first cassette contained an encephalomyocarditis virus internal ribosomal entry site (EMCV-IRES) that enabled gene expression under the control of an upstream endogenous RNA polymerase I promoter. LoxP sequences were inserted on either sides of the first cassette to enable insertion via homologous recombination. The plasmid was verified by DNA sequencing.

\section{Targeting of $I L 24$ at the rDNA locus in iPSCs}

We previously designed TALENickase by introducing mutations into the FokI domain sequence that generates DNA single-strand breaks (SSB) [31]. TALENickase improved site-specific integration efficiency of pHrneo at the rDNA locus and demonstrated comparatively lower cytotoxicity and offtarget mutagenesis compared to conventional double strand breaks (DSB) inducing TALENs. Therefore, pHrn-IL24 and TALENickases were co-nucleofected into the iPSCs. Further, to improve single cell survival, we added $10 \mu \mathrm{M}$ Y-27632 (rho-associated kinase (ROCK) inhibitor) $2 \mathrm{~h}$ before nucleofection into the medium and maintained it further for $24 \mathrm{~h}$ after nucleofection. Then, after 6 days, we conducted two independent selection experiments with $50 \mu \mathrm{g} / \mathrm{ml} \mathrm{G} 418$ and obtained sixty eight
G418-resistant clones. Finally, analysis of 31 G418resistant clones PCR and southern blot demonstrated that four transformed iPSC clones had the target transgene (Figure 1B-1E).

\section{Expression of exogenous IL24 in iPSCs}

The analysis of G-banded chromosomes in the four positive iPSC clones by genotyping showed that their karyotypes were normal and similar to normal iPSCs (Figure 2A). Then, we determined if the IL24 transgene was expressed in the iPSCs by qRT-PCR with primers designed to amplify exons 6 and 7 of IL24. As expected, the transcription of IL24 in the transformed iPSCs was significantly higher than in the control iPSCs (Figure 2B). Next, we determined the expression levels of IL24 protein in the supernatant and cell lysates by ELISA and Western blotting. Quantitative analysis showed that IL24 protein of targeted iPSCs was significantly increased compared to control iPSCs (Figure 2C to $2 \mathrm{E}$ ). In the supernatant, IL24 in the transformed iPSCs was between 15-26ng $/ 10^{6}$ cells compared to $6 \mathrm{ng} / 10^{6}$ cells in control iPSCs in $24 \mathrm{~h}$. In cell lysates, the expression of IL24 in transformed iPSCs was nearly 2 fold higher than the control iPSCs. These data demonstrated that the integrated IL24 transgene expressed efficiently in the transformed iPSCs.

\section{Generation and characterization of MSCs derived from IL24-iPSCs and iPSCs}

Then, we differentiated the IL24-iPSC line (IL243-4) with high IL24 expression and a control iPSC line into IL24-iMSCs and control iMSCs, respectively. During differentiation, IL24-iPSCs and control iPSCs were dissociated and treated with MSC differentiation medium containing epidermal growth factor (EGF) and platelet derived growth factor BB (PDGF-BB), both of which stimulate differentiation of iPSCs into MSCs. After 2 weeks of differentiation, confluent cells were passaged and cultured on gelatinized plates with MSC culture media and allowed to proliferate. We observed that after 4 passages, the induced iPSCs uniformly displayed fibroblast-like morphology that was similar to MSCs (Figure 3A) and different from iPSCs. Further, analysis of cell surface markers of IL24-iMSCs and iMSCs by flow cytometry showed that they were $\mathrm{CD} 44^{+} \mathrm{CD} 73^{+} \mathrm{CD} 90^{+} \mathrm{CD} 105^{+} \mathrm{CD} 34^{-}$ $\mathrm{CD}^{-} 5^{-}$and similar to human bone marrow MSCs (Figure 3B). We then tested the differentiation potential of IL24iMSCs and iMSCs and found that nearly $80-90 \%$ cells were positive for osteogenic, chondrogenic and adipocytic differentiation based on histochemical staining (Figure 3C). These results demonstrated that IL24-iPSCs and iPSCs differentiated efficiently into MSCs. 
A

Targeting construction
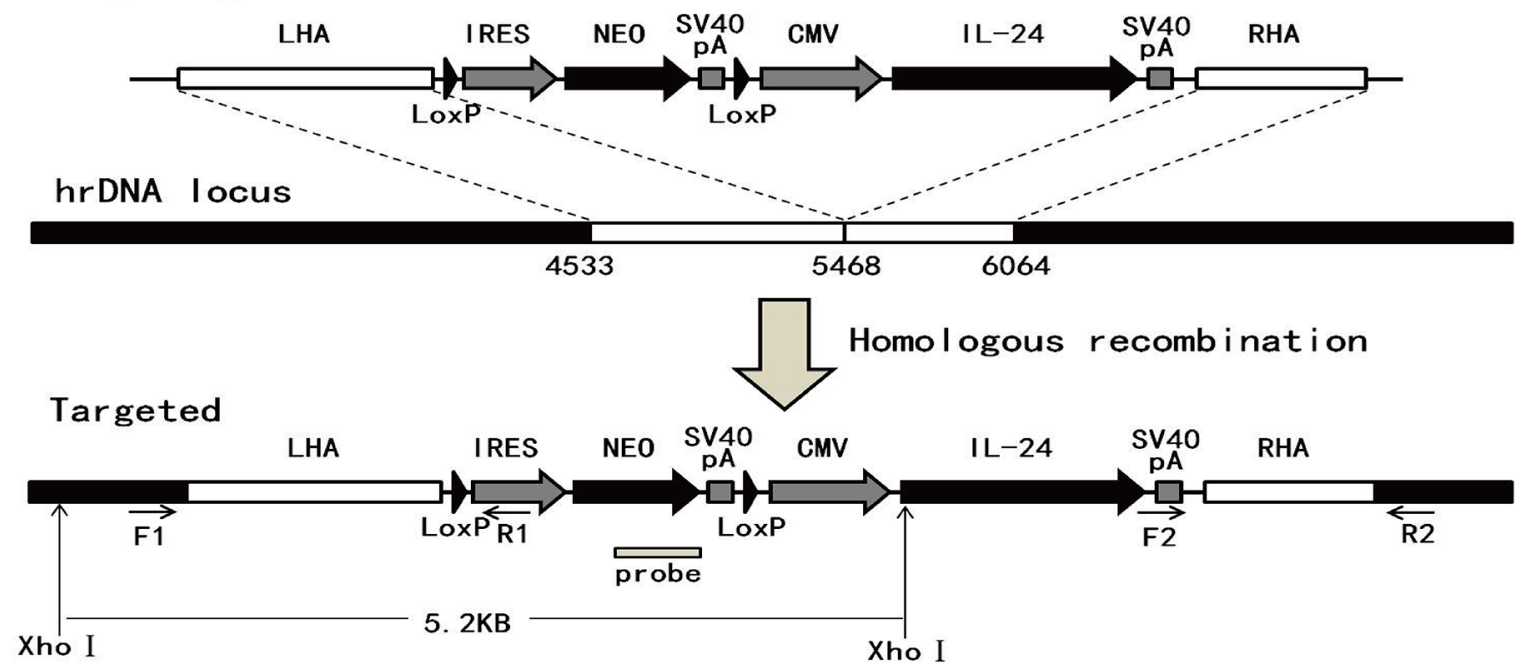

B

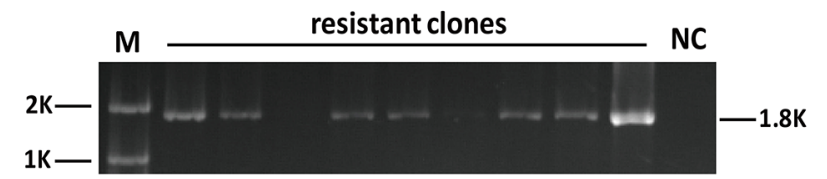

fragments 1 of $F 1 \times R 1$

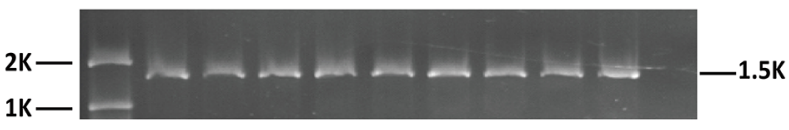

fragments 2 of $F 2 \times R 2$

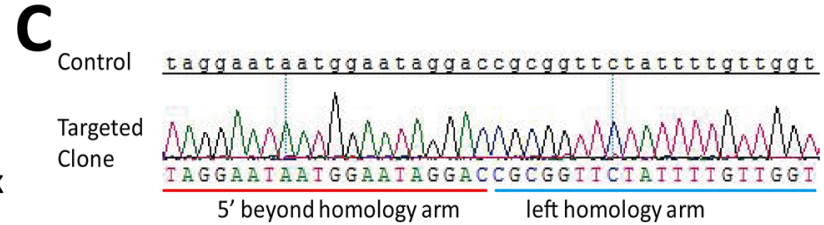

sequencing results of fragment 1

Control gctagggcgtctcgagggtcgggggccggacgccggtccc

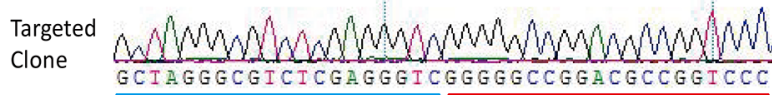

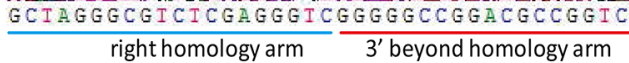

sequencing results of fragment 2

D
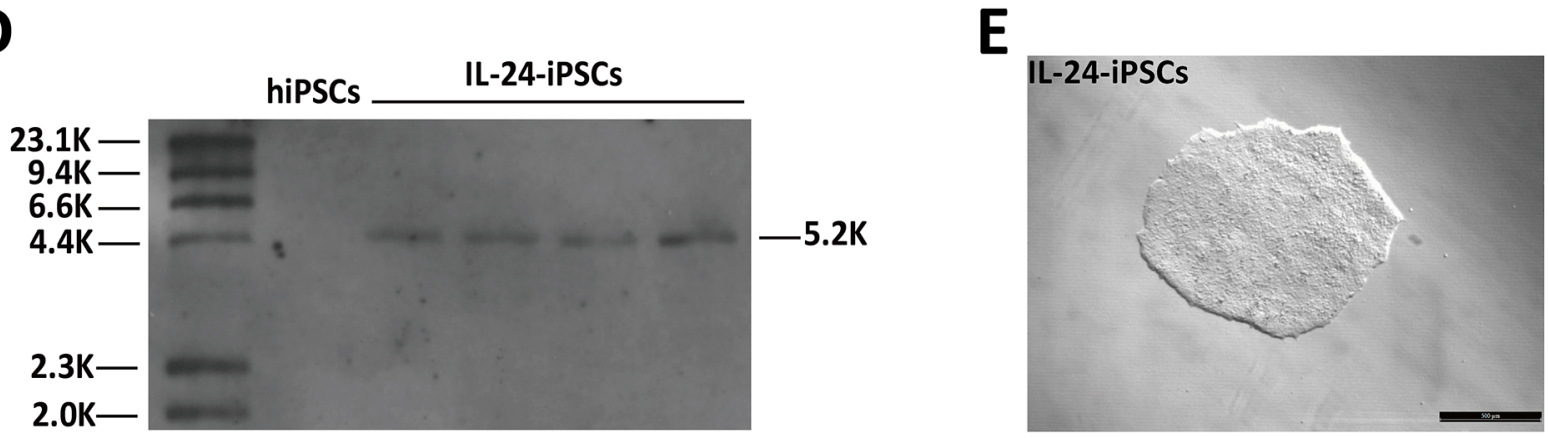

Figure 1: Analysis of site-specific integration of pHrn-IL24 at the rDNA locus of iPSCs. (A) Schematic representation of the gene targeting vector, the rDNA unit and targeted allele after homologous recombination is shown. The left (GenBank U13369: 4533-5467) and right (GenBank U13369: 5468-6064) homologous arms are shown by white boxes. The neomycin cassette consists of an IRES element from the encephalomyocarditis virus, the coding region of the neomycin gene (NEO), and SV40 polyA signal (SpA). Neo lacks a promoter. Gene expression is activated by the promoter of the endogenous rRNA genes after homologous recombination. The neomycin open reading frame (NEO ORF) was knocked-in into the rDNA unit resulting in an additional Xhol site that results in $5.2 \mathrm{~kb}$ fragment after digestion with XhoI. The IL24 gene is driven by a CMV promoter. Primers F1/R1 bind to the 18S RNA coding sequence beyond the homologous sequence and the IRES element; primers F2/R2 bind to the SV40 polyA signal and the 5.8S RNA coding sequence beyond the homologous sequence, respectively. (B) PCR screening for the G418 resistant clones were screened by PCR with F1/R1 and F2 $/ \mathrm{R} 2$ pairs that would generate $1.8 \mathrm{~kb}$ and $1.5 \mathrm{~kb}$ PCR products, respectively, if the cells underwent homologous recombination. (C) DNA sequencing of the two PCR products is shown. Both fragments were consistent with the expected theoretical sequences. (D) The positive clones (based on PCR) were confirmed by Southern blot analysis of the XhoI digested genomic DNA. Southern blot analysis showed a 5.2 $\mathrm{kb}$ band for transformed iPSCs clones with the designed probe. (E) Morphology of a representative IL24-iPSCs clone. Abbreviations: M, markers; NC, negative control. 


\section{IL24-iMSCs induce melanoma cell apoptosis in vitro}

IL24 expression was quantitated by ELISA and western blot analysis in IL24-iMSCs. IL24 levels were 4.2 fold higher in the supernatant of IL24-iMSCs than control iMSCs and 7 fold higher than in the control iPSCs (Figure 4A-4C). Comparatively, IL24 expression was 2 fold higher in the IL24-iMSC cell lysates compared to control iMSCs (Figure 4A-4C). However, no significant difference was observed in IL24 expression between control iPSCs and iMSCs suggesting that differentiation of iPSCs into MSCs did not increase endogenous levels of IL24.

Then, we determined if the IL24-iMSCs efficiently induced in vitro melanoma cell apoptosis by co-culturing IL24-iMSCs and B16-F10, a mouse melanoma cell line in a transwell system. After 7 days of co-culturing, cells were stained with AnnexinV-FITC/PI and B16-F10 cell apoptosis was analyzed by flow cytometry. We observed that the apoptosis rate of B16-F10 cells co-cultured with IL24-iMSCs was nearly 4.6 fold higher than B16-F10 cells co-cultured with control iMSCs and 8.9 fold higher than B16-F10 cells cultured alone (Figure 4D-4E). These data indicated that both IL24-iMSCs and iMSCs induced in vitro apoptosis in melanoma cells and IL24-iMSCs were more effective than the control iMSCs.

\section{IL24-iMSCs inhibit in vivo melanoma growth}

For in vivo studies, IL24-iMSCs and iMSCs were labeled with the fluorescent dye CM-Dil with $>90 \%$ efficiency. Previous studies have reported that CM-Dil does not alter viability, proliferation or differentiation of cells $[32,33]$. To determine the in vivo effect of IL24iMSCs on tumorigenesis, C57BL/6 mice were injected with mouse melanoma cells (B16-F10 cell line) and an equal number of CM-Dil labeled IL24-iMSCs or control iMSCs ( $\mathrm{n}=4$ each). Control mice were transplanted with CM-Dil labeled IL24-iMSCs only $(n=4)$ or CM-Dil labeled iMSCs only $(n=4)$ or B16-F10 cell line only $(n=$ 6). Mice transplanted with either IL24-iMSCs or control iMSCs alone did not form any tumors. Mice transplanted with the B16-F10 cell line only formed tumors by day 7 with an average tumor volume of $2921.50 \mathrm{~mm}^{3}$ on day

A

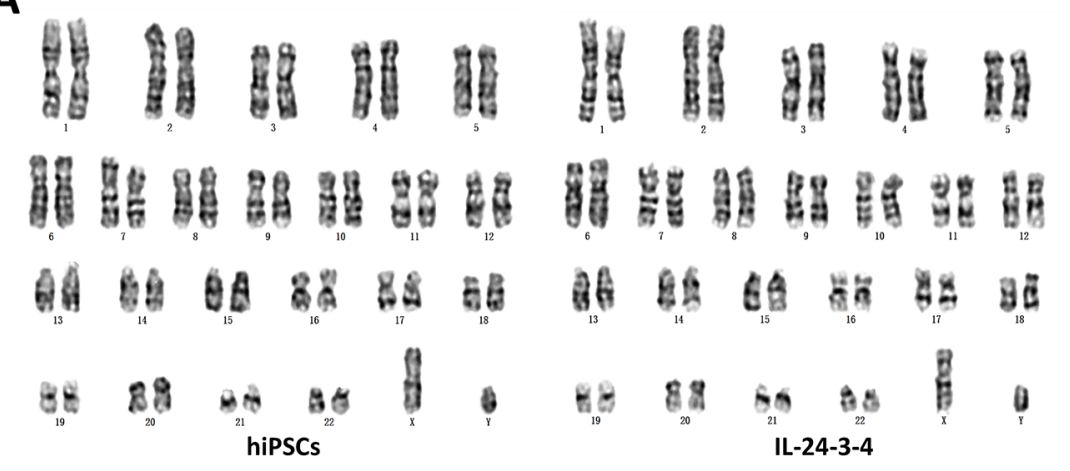

B

C

D

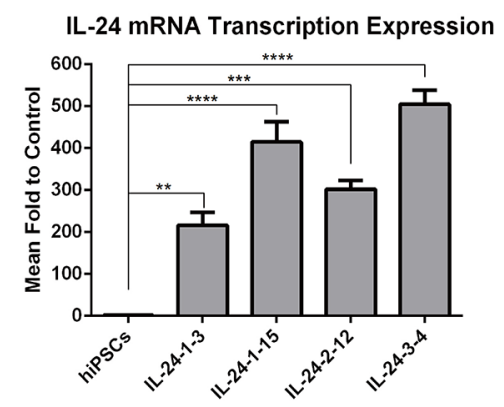

E

IL-24 Expression in Supernatant
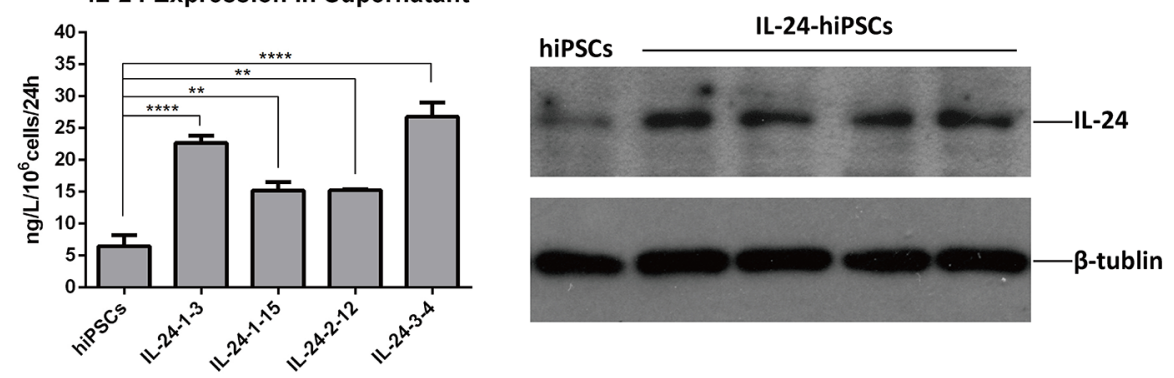

IL-24 Expression in Cell Lysate

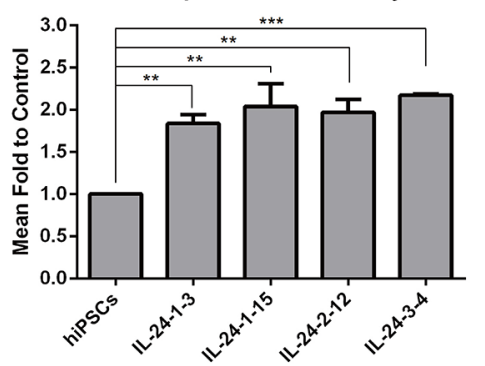

Figure 2: Analysis of IL24 expression in tranformed iPSCs. (A) The transformed iPSC clones showed a normal karyotype (46, XY) (right) consistent with the normal iPSCs (left); $\mathrm{n}=5$ for each group. (B) Detection of IL24 mRNA transcription levels in control hiPSC and positively transformed hiPSC lines (IL-24-1-3; IL-24-1-15; IL-24-2-12; IL-24-3-4) by qRT-PCR. The IL24 levels in targeted iPSCs were higher than normal iPSCs. (Data are mean \pm SEM, $\mathrm{n}=3$ for each group. ${ }^{* *} \mathrm{p}<0.01, * * * \mathrm{p}<0.001, * * * * \mathrm{p}<0.0001$, One-way ANOVA.) (C) ELISA analysis of the supernatant of clones from control iPSC and positively transformed iPSC lines. The levels of secreted IL24 in different transformed iPSC clones was in the range of $15-26 n g / 10^{6}$ cells in $24 \mathrm{~h}$ respectively. (Data are mean $\pm S E M, n=4$ for each group. ${ }^{*} \mathrm{p}<0.01, * * * * \mathrm{p}<0.0001$, One-way ANOVA.) (D and E) Western blot analysis of cell lysates of clones from control hiPSC and transformed iPSC lines. The expression level of IL24 in the 4 transformed clones was about 2 fold higher than in iPSCs. (Data are mean \pm $\mathrm{SEM}, \mathrm{n}=3$ for each group. $* * \mathrm{p}<0.01, * * * \mathrm{p}<0.001$, One-way ANOVA.). 
19. Mice injected with both B16-F10 cells and iMSCs developed detectable tumors on day 7 with an average tumor volume of $2223.51 \mathrm{~mm}^{3}$ on day 19 . In contrast, mice injected with both B16-F10 cells and IL24-iMSCs developed detectable tumors on day 9 with an average tumor volume of $643.64 \mathrm{~mm}^{3}$ on day 19, thereby demonstrating the inhibitory effects of IL24-iMSCs on tumor development (Figure 5A). Tumor weights were recorded immediately upon harvesting from mice on day 19. The volume of tumor in the control mice injected with B16-F10 cells was 3.6 fold larger than mice injected with both B16-F10 cells and IL24-iMSCs and 1.4 fold larger than mice injected with both B16-F10 cells and iMSCs (Figure 5B). Meanwhile, the weight of tumor in the control mice injected with B16-F10 cells was 6.3 fold larger than mice injected with both B16-F10 cells and IL24-iMSCs

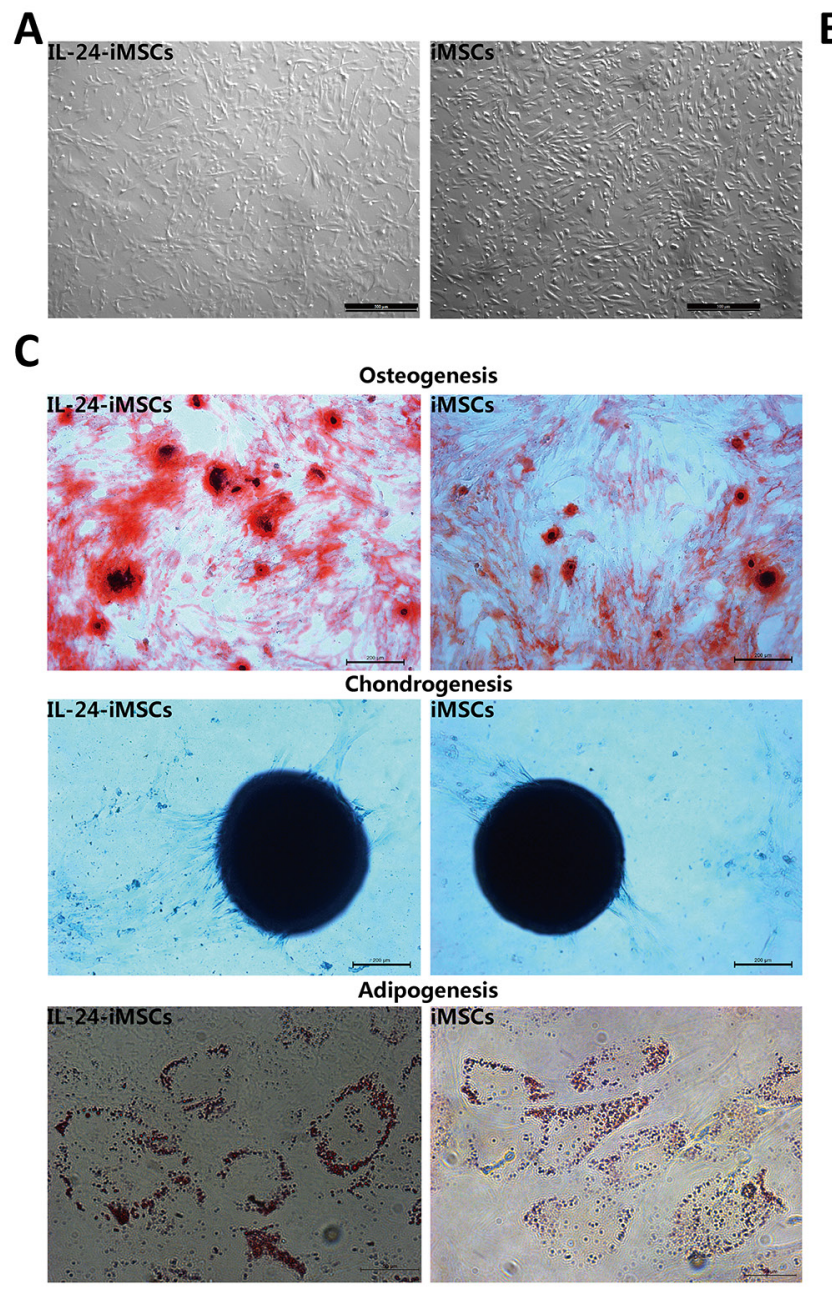

and 1.3 fold larger than mice injected with both B16-F10 cells and iMSCs (Figure 5C).

Immunofluorescence analysis of the tumors revealed that CM-Dil-positive IL24-iMSCs expressed human IL24 in the mouse melanomas (Figure 5D). In situ pathological examination of $\mathrm{H} \& \mathrm{E}$ stained tumor tissues from the mice injected with B16-F10 cells and either IL24-iMSCs or iMSCs showed necrotic areas and aggregation of cell nuclei in the tumor area (Figure 5E). Comparatively, the necrotic areas in the tumors from the IL24-iMSC group were larger than the iMSC group suggesting the apoptotic effects of transgenic IL24.

\section{DISCUSSION}

Nearly two-thirds of the clinical trials in gene therapy are aimed at the treatment of various types of

\section{B}

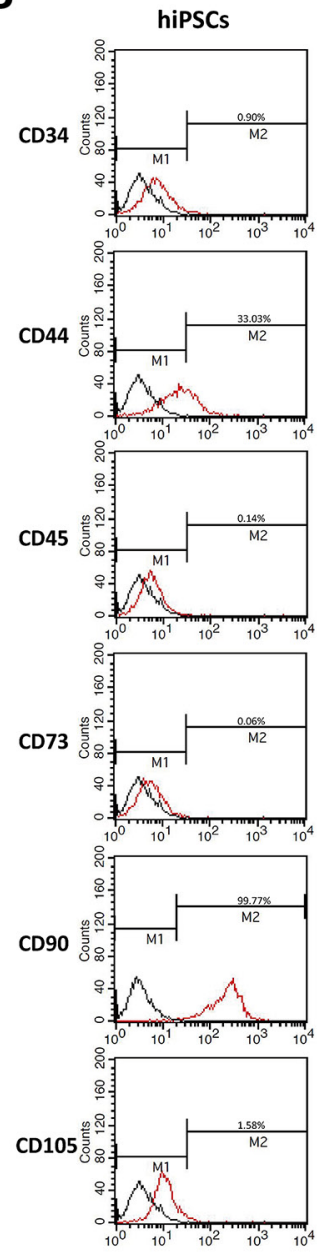

IL-24-iMSCS

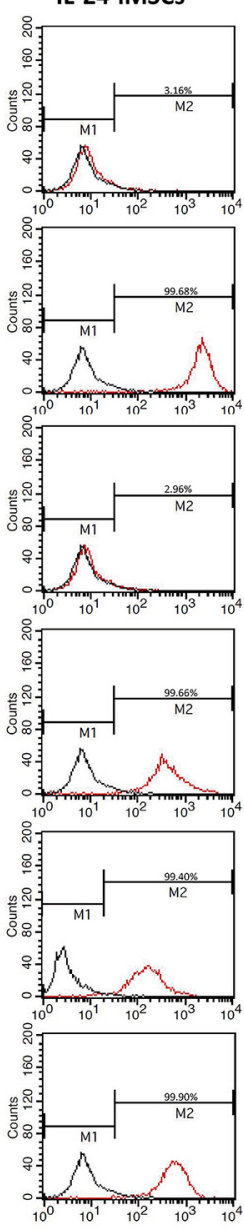

Figure 3: Generation and characterization of iMSCs. (A) Morphology of the MSCs derived from IL24-iPSCs and control iPSCs. (B) Flow cytometric analysis of surface markers in human MSCs, iPSCs, iPSCs derived MSCs and IL24-iPSCs-derived MSCs. Black curves represent isotype controls and red curves represent the specific antibodies. ( $\mathrm{n}=3$ for each group). (C) Analysis of adipogenic, osteogenic, and chondrogenic differential potential of IL24-iMSCs and iMSCs. The osteogenic cultures were stained with alizarin red S (Cyagen Biosciences, China) to detect calcium deposition. For chondrogenic induction, the pellet sections were stained with alcian blue dye (Cyagen Biosciences, China) to detect proteoglycans. The adipogenic cultures were stained with oil red O (Cyagen Biosciences, China) to measure the accumulation of intracellular lipids. ( $\mathrm{n}=3$ for each group). 
cancers and in viral vectors are used in most cases [34]. However, issues regarding safety concerns and loss or silencing of the inserted transgenes are encountered when viral vectors are used. In previous studies, we developed a non-viral gene targeting system that efficiently inserted into the rDNA locus of multiple cell types, including human ESCs and MSCs [16-18]. Engineered nucleases such as TALENs profoundly increase gene targeting frequency via double-strand break (DSB) [35]. However, since multiple DSBs generated by TALENs in multiple rDNA loci are likely to be fatal, we previously generated TALENickases which led to less off-target mutagenesis and cytotoxicity by creating SSB, it was more effective than TALENs in improving gene targeting at the rDNA locus [31]. In the present study, we efficiently targeted IL24 into the rDNA locus of human iPSCs using the rDNA targeting vector and TALENickases, with a relative targeting efficiency of nearly $13 \%$ in two independent experiments.
Currently, there exist concerns regarding if MSCs suppress or promote tumor growth. Although some studies have demonstrated that MSCs migrate to tumor sites and promote tumor growth, the underlying mechanisms remain obscure $[36,37]$. However, owing to their ability to migrate to tumor locations, MSCs represent promising tools to deliver therapeutic agents to cancer sites [8, 38-44]. Many studies have demonstrated that genetically engineered MSCs inhibit tumor growth in lung cancer, melanoma, glioma, liver cancer and breast cancer [41, $42,45,46]$. In a previous study we targeted neomycin gene into the rDNA locus of hBM-MSCs and generated stably transformed hBM-MSCs with G418 selection [17]. We also demonstrated proliferation of transformed hBMMSCs upon culturing [17]. Therefore, a new strategy was necessary to rapidly obtain abundant transformed MSCs for clinical applications, whenever necessary.

The purpose of this study was to verify if MSCs derived from transformed iPSCs could serve as cellular vehicles to exert anti-tumor effects in vivo. Many studies
A

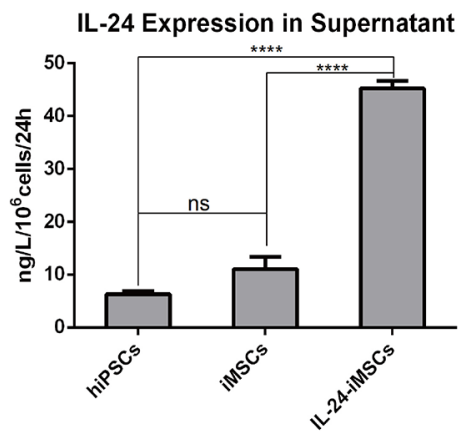

D

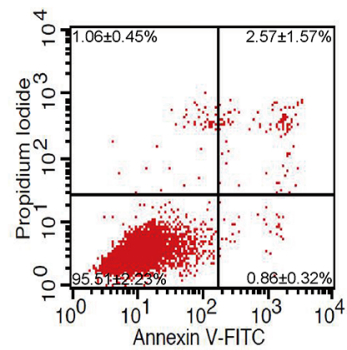

B16-F10
B

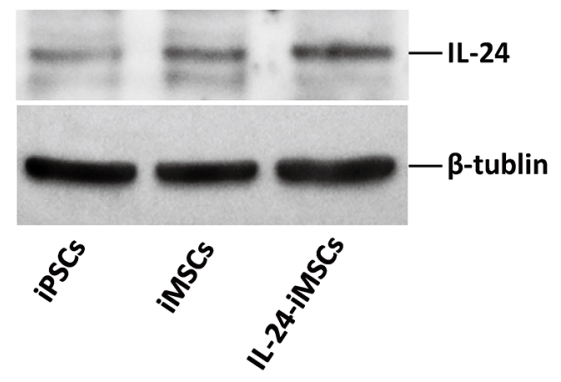

$E$

Transwell Co-culture Induced Cells Apoptosis

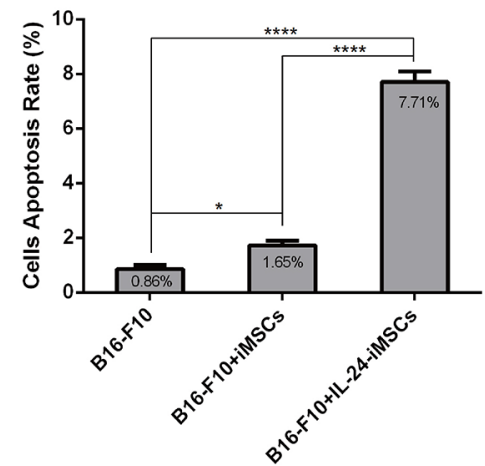

Figure 4: IL24-iMSCs induce in vitro melanoma cell apoptosis. (A) ELISA analysis of IL24 in the supernatants from iMSCs and IL24-iMSCs is shown. IL24 levels in the supernatants of iPSCs, iMSCs and IL24-iMSCs were 6.33 $\pm 0.97 \mathrm{ng}, 10.58 \pm 2.66 \mathrm{ng}$ and $45.18 \pm 2.53 \mathrm{ng}$, respectively in $10^{6}$ cells in $24 \mathrm{~h}$. (Data are mean \pm SEM; $\mathrm{n}=4$ for each group; $\mathrm{ns}, \mathrm{p}>0.05 ; * * * *, \mathrm{p}<0.0001$ by Oneway ANOVA). (B and C) Western blot analysis of cell lysates from control iMSCs and IL24-iMSCs. The expression levels of IL24 in IL24iMSCs were about 2 fold higher than in control iMSCs.(Data are mean \pm SEM; $\mathrm{n}=3$ for each group; $\mathrm{ns}, \mathrm{p}>0.05, * * *, \mathrm{p}<0.001, * * * *$, $\mathrm{p}<0.0001$, One way ANOVA). (D and E) Flow cytometric analysis of cell apoptosis assay. B16-F10 cells co-cultured with IL24-iMSCs showed increased apoptosis compared to co-culturing with control iMSCs or control B16-F10 cells in vitro. (Data are mean \pm SEM; $\mathrm{n}=3$ for each group; $* \mathrm{p}<0.05, * * \mathrm{p}<0.01, * * * \mathrm{p}<0.001, * * * * \mathrm{p}<0.0001$, One way ANOVA). 
A

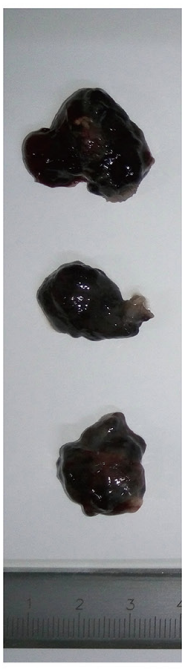

B16-F10

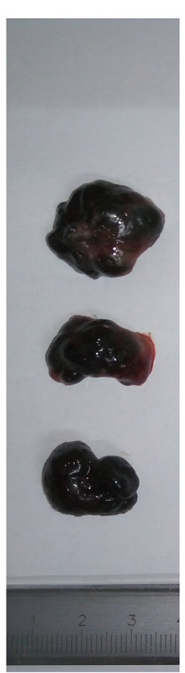

B16-F10+ iMSCs

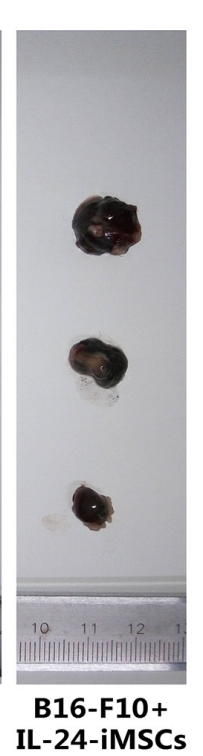

B

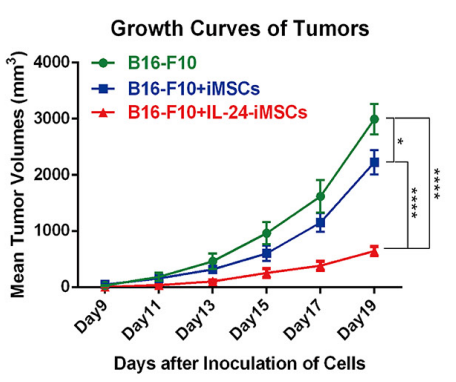

C

Weight Comparison of Different Tumor

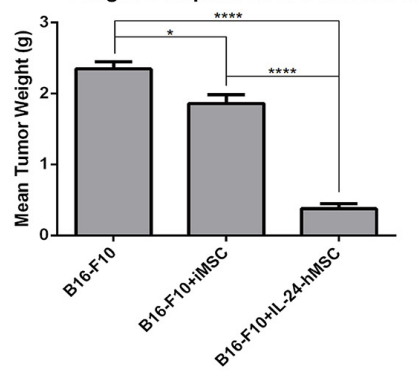

D

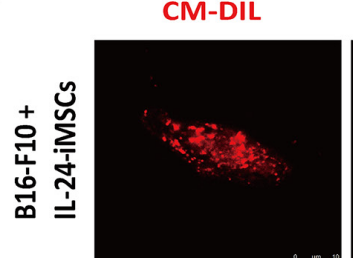

IL-24
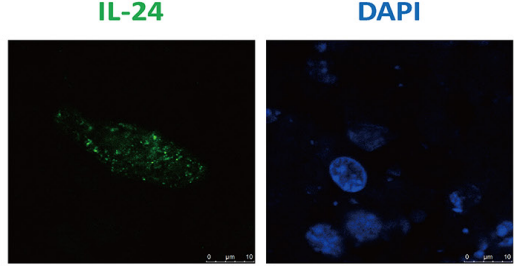

Merge
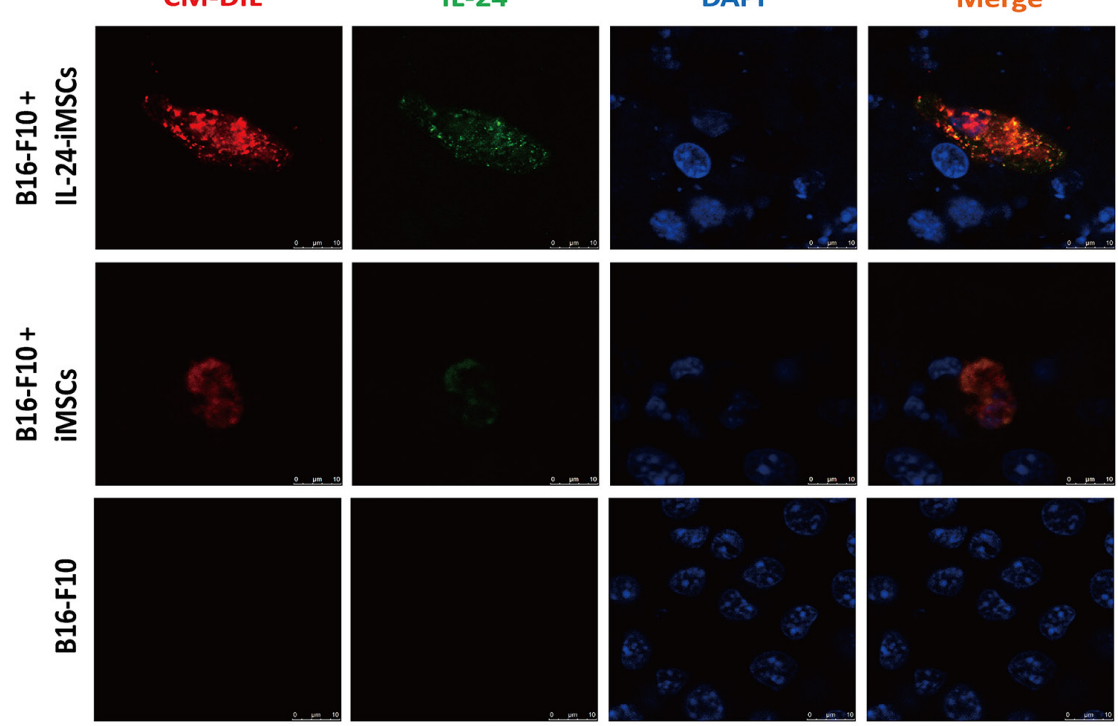

E
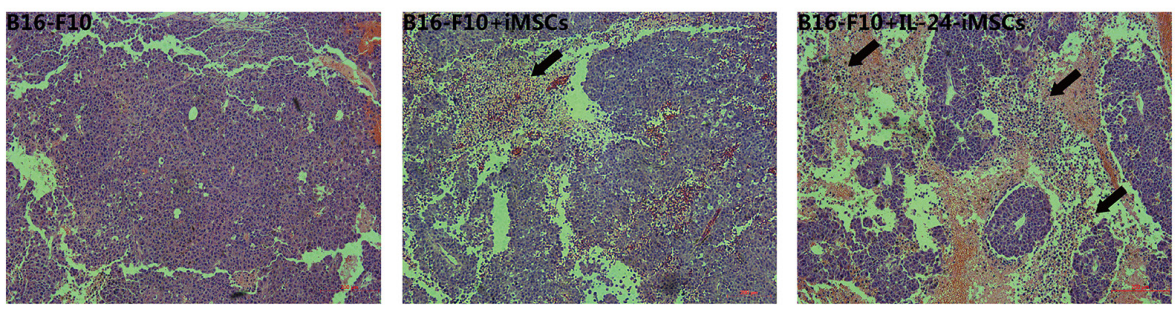

Figure 5: IL24-iMSCs in vivo suppressed melanoma growth. (A) Representative images of isolated tumors from mice injected

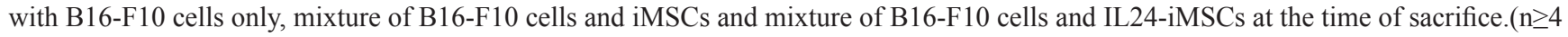
for each group) (B) Time course of tumor volume changes in mice injected with or without IL24-iMSCs at 19 days. Tumor sizes of mixture of B16-F10 cells and IL24-iMSCs group were significantly reduced. (Data are mean $\pm \mathrm{SEM} ; \mathrm{n} \geq 4$ for each group; $* \mathrm{p}<0.05, * * * * \mathrm{p}<$ 0.0001, One way ANOVA). (C) Measurement of tumor weights from C57BL/6 mice injected with or without IL24-iMSCs at the time of sacrifice. Tumor weights of mixture of B16-F10 cells and IL24-iMSCs group were significantly reduced. (Data are mean \pm SEM; $\geq 4$ for each group; $* \mathrm{p}<0.05, * * * * \mathrm{p}<0.0001$, One way ANOVA). (D) Immunofluorescence analysis with human specific IL24 antibody of tumor tissue sections derived from mice injected with B16-F10 cells in combination with either IL24-iMSCs or control iMSCs, or only B16-F10 cells. Melanoma sections examined for CM-Dil fluorescence (red), human IL24 protein fluorescence (green) and the cell population by DAPI staining (blue). (E) H\&E stained histological sections of tumors show more diffuse necrotic areas (arrow) in melanoma injected with IL24-iMSCs compared with control iMSCs group. ( $n=3$ for each group). 
demonstrated that IL24, a cytokine of the IL-10 family that was originally identified from metastatic human melanoma cells [20], induced cancer cell apoptosis $[19,43,47-49]$. There is increasing evidence that IL24 inhibits growth of many diverse human cancers including melanomas [29], breast cancer [44], pancreatic cancer [50], gliomas [51], hepatocellular cancers [52] and ovarian cancer [53] without adversely affecting normal cells or tissues. Therefore, we chose IL24 as the therapeutic gene in this study.

Our results revealed that both transformed iPSCs (IL24-iPSCs) and subsequently derived IL24-iMSCs efficiently expressed exogenous IL24 while retaining their cellular characteristics. Furthermore, both IL24iMSCs and iMSCs induced apoptosis in melanoma cells, thereby inhibiting melanoma growth in vivo. Our results are in accordance with other findings that have demonstrated anti-tumor properties of factors released from MSCs [42, 45]. More importantly, IL24-iMSCs suppressed tumor growth more effectively than control iMSCs demonstrating the anti-tumor effects of transgenic IL24. Therefore, we postulate that this non-viral gene targeting system in iPSCs and subsequent iMSCs represent great advantage in terms of safety and stability of IL24 expression and therefore need to be pursued further.

In summary, we targeted IL24 into the rDNA locus of human iPSCs using a combination of non-viral vector and TALENickases. Our studies demonstrated therapeutic efficacy of MSCs derived from the transformed iPSCs (with IL24 gene) in a mouse melanoma model. Thus, we provide the first proof of principle of generating transformed iPSCs by gene targeting with a non-viral vector and subsequent generation of genetically modified MSCs with enormous clinical potential for autologous cellular therapy in cancers.

\section{MATERIALS AND METHODS}

\section{Cell culture}

Human induced pluripotent stem cells (DYR0100) were purchased from ATCC and cultured in mTeSR 1 medium (STEMCELL Technologies, Canada) at $37^{\circ} \mathrm{C}$ in a humidified chamber maintained at $5 \% \mathrm{CO}_{2}$. DYR0100 were passaged every 5 days [54] before being plated onto a Matrigel (BD Biosciences, USA) coated dishes. The MSCs derived from iPSCs were cultured in MSC medium with DMEM/LG (HyClone, USA) supplemented with 10\% FBS (Gibco, USA). PMEF-NL fibroblasts (Millipore) were cultured in DMEM/HG (HyClone, USA) supplemented with $5 \%$ FBS, $2 \mathrm{mM} \mathrm{L-glutamine}$ (Invitrogen, USA) and 1\% non-essential amino acids (Invitrogen, USA). The murine melanoma cells B16-F10 (from a C57BL/6 strain) were purchased from ATCC and cultured in DMEM/HG supplemented with $10 \%$ FBS.

\section{Construction of pHrn-IL24 plasmid and transformation of iPSCs}

In our previous study, we constructed the non-viral human ribosomal DNA (hrDNA) targeting vector, pHrneo [16]. In this study, we optimized pHrneo by shortening the size of its left and right homology arms to 953bp and $596 \mathrm{bp}$, respectively and inserted a pair of loxP sequences on both sides of the neomycin expression cassette. Then, we PCR amplified the IL24 open reading frame (GenBank No. BC009681 249-872) from pHr-CMG vector constructed by our group [55], and inserted into the NheI restriction site of the optimized targeting vector to generate $\mathrm{pHrn}-I L 24$.

For gene targeting, the iPSCs were incubated at $37^{\circ} \mathrm{C}$ with TrypLE Select (Invitrogen, USA) for $3 \mathrm{~min}$ before harvesting and counting. Then, $3 \times 10^{6} \mathrm{iPSC}$ were resuspended in $100 \mu \mathrm{L}$ nucleofection buffer (Human Stem Cell Nucleofector Kit 2, Lonza, Switzerland) with $5 \mu \mathrm{g}$ linearized pHrn-IL24 and $5 \mu \mathrm{g}$ TALENickases as previously described [31]. Nucleofection was completed by NucleofectorII (Lonza, Switzerland) with program B016. The transfected cells were maintained on mitomycin-C treated PMEF cells in DMEM/F12 medium supplemented with $20 \%$ knockout serum replacement (Gibco, USA), 2mM L-glutamine, 1\% non-essential amino acids, $0.1 \mathrm{mM} \beta$-mercaptoethanol (Gibco, USA) and 10ng/ $\mathrm{ml}$ basic fibroblast growth factor (Invitrogen, USA). On the 6th day after transfection, selection was initiated by adding $50 \mu \mathrm{g} / \mathrm{ml} \mathrm{G418} \mathrm{(Sigma-Aldrich,} \mathrm{USA)} \mathrm{and} \mathrm{grown}$ for 9 days in selection media. The G418 resistant clones were then picked mechanically and expanded on Matrigel in mTeSR1 medium.

\section{PCR and $q R T-P C R$}

Genomic DNA was isolated from iPSCs by phenol/chloroform extraction method. PCR was performed using LA Taq DNA polymerase (TaKaRa, Japan) according to the manufacturer's recommendations. To identify the site-specific integration colonies, the following pairs of primers were used: F1:5'-CCTGAGAAACGGCTACCACATCC-3'/ R1:5'CATCCAAGGAAGGCAGCAGGC-3'; F2:5'-GAGCA TTCAAACAGTTGGACG-3'/ R2:5'-GATCCACCGCT AAGAGTCGTAC-3'. The annealing Temperature of $\mathrm{F} 1 \mathrm{R} 1$ and $\mathrm{F} 2 \mathrm{R} 2$ are $59^{\circ} \mathrm{C}$ and $58^{\circ} \mathrm{C}$. Total RNA was extracted using TRIzol reagent (Sigma-Aldrich, USA) and treated with DNaseI (Thermo Fisher Scientific, USA) to eliminate genomic and other DNA. The qRT-PCR for each 50ng RNA sample was performed using HiScript II One Step qRT-PCR SYBR Green Kit (Vazyme, China) on Bio-Rad CFX96 touch qPCR system (Bio-Rad, USA) according to the manufacturer's instructions. The RNA samples were subjected to 40 cycles of amplification after $30 \mathrm{~min}$ of reverse transcription at $50^{\circ} \mathrm{C}$. The 
data analysis was performed using the Bio-Rad CFX Manager software (Bio-Rad, USA). The hypoxanthine phosphoribosyltransferase (HPRT) gene was amplified as an internal control. The IL24 qRT-PCR primers are as follows: 5'-CAGGCGGTTTCTGCTATTC-3'/ 5'-GAATTTCTGCATCCAGGTCA-3'. The annealing Temperature of primers is $60^{\circ} \mathrm{C}$.

\section{Southern blotting}

$5 \mu \mathrm{g}$ genomic DNA was digested with XhoI restriction enzyme (New England Biolabs, USA) overnight and then electrophoresed on a $0.8 \%$ agarose gel for $3 \mathrm{~h}$ at $180 \mathrm{~V}$ followed by transfer to a positively charged nylon membrane (Roche Diagnostics, Switzerland) by capillary siphon blotting overnight. DNA molecular weight marker III, digoxigenin (DIG) -labeled DNA (Roche Diagnostics, Switzerland) and lambda DNA Hind III (TaKaRa, Japan) were used as molecular weight markers. The blots were then blocked and then hybridized with DIG-dUTP labeled probes overnight at $42^{\circ} \mathrm{C}$. This was followed by incubation with AP-conjugated DIGantibody (Roche Diagnostics, Switzerland) for $30 \mathrm{~min}$. After thorough washing, the signals were detected using CDP-Star (Roche Diagnostics, Switzerland) as a substrate for chemiluminescence. Probes were generated by PCR DIG Probe Synthesis Kit (Roche Diagnostics, Switzerland) using the primer pairs, 5'-GCCGAGAAAGTATCCATCA-3'/ 5'-CAGAGTCCCGCTCAGAAG-3'.

\section{Karyotyping}

Three-day-old iPSCs and IL24-iPSCs cell clumps were treated with $0.08 \mu \mathrm{g} / \mathrm{ml}$ colcemid (SigmaAldrich, USA) for $2.5 \mathrm{~h}$. The cells were then trypsinized, centrifuged, and incubated in $0.075 \mathrm{M} \mathrm{KCl}$ for $30 \mathrm{~min}$ at $37^{\circ} \mathrm{C}$. After fixing with Carnoy's fixative (Methanol : Acetic Acid = 3:1, Sinopharm Chemical Reagent, China), metaphase chromosome spreads were prepared using air drying.

\section{ELISA}

After culturing iPSCs in mTeSR1 medium for 3 days, 24h-old supernatants were collected from sixwell plates. Total cells were trypsinized and counted. All supernatants were collected in triplicate. ELISA was performed using paired antibodies for ELISA-IL24 (dilution of 1:100, goat polyclonal, Catalog\# AF1965, R\&D Systems, USA) according to the manufacturer's instructions.

\section{Western blotting}

Tatal lysate samples of iPSCs and MSCs were prepared by RIPA Lysis Buffer (Beyotime, China) and quantified by BCA Protein Quantification Kit (Beyotime, China). Each $20 \mu \mathrm{g}$ cell protein lysate sample was loaded for electrophoresis for $2 \mathrm{~h}$ at $120 \mathrm{~V}$ and electrotransferred for $1.5 \mathrm{~h}$ at $290 \mathrm{~mA}$ onto PVDF membranes (Millipore, USA). Membranes were incubated overnight with primary anti-human IL24 antibody (dilution of 1:1000, goat polyclonal, Catalog\# AF1965, R\&D Systems, USA) and anti-human $\beta$-Tubulin antibody (dilution of 1:5000, mouse monoclonal, Catalog\# T8328, Sigma-Aldrich, USA) at $4{ }^{\circ} \mathrm{C}$. After thorough washing, the membranes were incubated with the horseradish peroxidase-conjugated anti-goat (dilution of 1:10000, Catalog\# 805-035-180, Jackson ImmunoResearch) and anti-mouse secondary antibodies (dilution of 1:10000, Catalog\# 115-035-146, Jackson ImmunoResearch) for $1 \mathrm{~h}$ at room temperature and detected by autoradiography using the ECL system (Millipore, USA). Prestained molecular weight standards (Thermo Fisher Scientific, USA) were used to estimate the apparent molecular weight.

\section{Generation and characterization of MSCs derived from iPSCs}

For differentiation of iPSCs into MSCs, we optimized an established protocol [14]. Briefly, a confluent $6 \mathrm{~cm}$ dish of iPSCs was trypsinized and seeded at a density of $1 \times 10^{4}$ cells $/ \mathrm{cm}^{2}$ in a matrigel coated 6-well tissue culture plate in mTeSR 1 medium. When the cells reached $60 \%-70 \%$ confluence, the culture medium was changed to MSC differentiation medium that was composed of knockout DMEM (Gibco, USA) supplemented with 10\% knockout serum replacement, 1\% non-essential amino acids, $2 \mathrm{mM}$ L-glutamine, $0.1 \mathrm{mM} \beta$-mercaptoethanol, 20ng/ml bFGF, 20ng/ml EGF (Life Technologies, USA) and PDGF-BB (PeproTech, USA). After three passages, the differentiated cells were trypsinized and seeded in gelatinized 6-well tissue culture plates in MSC culture medium (DMEM/LG supplemented with 10\% FBS and $2 \mathrm{mM}$ L-glutamine).

The surface antigen profiling of IL24-iMSCs and iMSCs was characterized by flow cytometry after incubated 30min with fluorescently tagged anti-human PECD34, PE-CD44, PE-CD45, PE-CD73, FITC-CD90, and PE-CD105 (dilution of 1:20, Catalog\# 550761, 550989, 555483, 550257, 555595, 560839, BD Biosciences, USA) at $37^{\circ} \mathrm{C}$ according to the manufacturer's instructions. Differentiation of IL24-iMSCs and iMSCs was carried out using Osteogenesis, Chondrogenesis and Adipogenesis differentiation kits (Invitrogen, USA) according to the manufacturer's protocol.

\section{Apoptosis detection}

To quantify apoptosis, $3 \times 10^{4} \mathrm{~B} 16-\mathrm{F} 10$ cells were seeded in the upper transwell chamber of a 6 well 
transwell plate $(0.4 \mu \mathrm{m}$ PET MEM, Corning, USA) and $9 \times 10^{4}$ IL24-iMSCs or control iMSCs were seeded in the lower transwell chamber. The plates were incubated at $37^{\circ} \mathrm{C}$ and $5 \% \mathrm{CO}_{2}$. After 7 days of co-culturing in the same medium, B16-F10 cells were harvested and stained with AnnexinV-FITC/PI Apoptosis Detection Kit (Vazyme, China) according to the manufacturer's instructions followed by flow cytometry and analysis to estimate the percentage of apoptotic cells (AnnexinVpositive).

\section{Mouse xenograft assays and iMSC cell tracking in tumors}

IL24-iMSCs and iMSCs were labeled with $5 \mu \mathrm{M}$ CM-Dil (Invitrogen, USA) according to the manufacturer's instructions. After labeling, cells were washed with PBS and cultured in MSC culture medium. The labeling efficiency was examined with a fluorescent microscope. Male C57BL/6 mice (4-6 weeks old) were obtained from the Center of Experimental Animals, Shanghai Institutes for Biological Sciences and kept in pathogen free conditions. All animal procedures were approved by the Ethics Committee for Animal Experimentation of Central South University. The mice were divided into five groups ( $\mathrm{n}>4$, for each group). The test group was treated with a mixture of CM-Dil labeled IL24-iMSCs $\left(5 \times 10^{5}\right)$ and B16-F10 cells $\left(5 \times 10^{5}\right)$. In the control groups, CMDil labeled IL24-iMSCs $\left(5 \times 10^{5}\right)$, CM-Dil labeled iMSCs $\left(5 \times 10^{5}\right)$, B16-F10 cells $\left(5 \times 10^{5}\right)$, CM-Dil labeled iMSCs $\left(5 \times 10^{5}\right)$ mixed with B16-F10 cells $\left(5 \times 10^{5}\right)$ were injected separately. For all groups, cells were resuspended in $0.1 \mathrm{ml}$ medium and subcutaneously injected into the groin region of anesthetized C57BL/6 mice. Tumor size was measured by vernier calipers every 2 days, and tumor volume was calculated with the formula $\left[\mathrm{V}=\left(\mathrm{W}^{2} \times \mathrm{L}\right) / 2\right]$ in cubic millimeters, where $\mathrm{W}$ and $\mathrm{L}$ are the shortest and longest diameter.

\section{Immunofluorescence and histological analysis}

The mice were sacrificed on the $19^{\text {th }}$ day after xenografting by cervical dislocation under anesthesia with diethyl. Tumors were harvested, photographed, weighed, and fixed with $4 \%$ paraformaldehyde. Half of the tumors were used for frozen sections $(10 \mu \mathrm{m}$ thickness). For immunofluorescence detection of IL24, sections were incubated with anti-human IL24 antibody (dilution of 1:100, goat polyclonal, Catalog\# AF1965, R\&D Systems, USA), followed by incubation with fluorescent AF488anti-goat secondary antibody (dilution of 1:100, Catalog\# 205-545-108, Jackson ImmunoResearch). CM-Dil and fluorescence staining was visualized and acquired by the confocal fluorescent microscopy. Paraffin sections (4 $\mu \mathrm{m}$ thickness) were stained with hematoxylin and eosin (H\&E) for histological examination.

\section{Statistical analysis}

The Student's t-test and one-way ANOVA were used for data analysis of different experimental groups by GraphPad Software. Data were expressed as the mean \pm standard error of the mean. $\mathrm{P}<0.05$ was considered statistically significant.

\section{ACKNOWLEDGMENTS}

The present research was supported by The National Natural Science Foundation of China (81272540, 81271944, 31571313), The National Key Research and Development Program of China (2016YFC0905100) and The Natural Science Foundation of Hunan Province of China (11JJ4023).

\section{CONFLICTS OF INTEREST}

The authors declare no conflicts of interest exists.

\section{REFERENCES}

1. Prockop DJ. Repair of tissues by adult stem/progenitor cells (MSCs): controversies, myths, and changing paradigms. Mol Ther. 2009; 17:939-946.

2. Xin H, Kanehira M, Mizuguchi H, Hayakawa T, Kikuchi T, Nukiwa T, Saijo Y. Targeted delivery of CX3CL1 to multiple lung tumors by mesenchymal stem cells. Stem Cells. 2007; 25:1618-1626.

3. Menon LG, Picinich S, Koneru R, Gao H, Lin SY, Koneru M, Mayer-Kuckuk P, Glod J, Banerjee D. Differential gene expression associated with migration of mesenchymal stem cells to conditioned medium from tumor cells or bone marrow cells. Stem Cells. 2007; 25:520-528.

4. Loebinger MR, Eddaoudi A, Davies D, Janes SM. Mesenchymal stem cell delivery of TRAIL can eliminate metastatic cancer. Cancer research. 2009; 69:4134-4142.

5. Khakoo AY, Pati S, Anderson SA, Reid W, Elshal MF, Rovira, II, Nguyen AT, Malide D, Combs CA, Hall G, Zhang J, Raffeld M, Rogers TB, et al. Human mesenchymal stem cells exert potent antitumorigenic effects in a model of Kaposi's sarcoma. The Journal of experimental medicine. 2006; 203:1235-1247.

6. Belmar-Lopez C, Mendoza G, Oberg D, Burnet J, Simon C, Cervello I, Iglesias M, Ramirez JC, Lopez-Larrubia P, Quintanilla M, Martin-Duque P. Tissue-derived mesenchymal stromal cells used as vehicles for anti-tumor therapy exert different in vivo effects on migration capacity and tumor growth. BMC Med. 2013; 11:139.

7. Kidd S, Caldwell L, Dietrich M, Samudio I, Spaeth EL, Watson K, Shi Y, Abbruzzese J, Konopleva M, Andreeff M, Marini FC. Mesenchymal stromal cells alone or expressing interferon-beta suppress pancreatic tumors in vivo, an effect 
countered by anti-inflammatory treatment. Cytotherapy. 2010; 12:615-625.

8. Gao P, Ding Q, Wu Z, Jiang H, Fang Z. Therapeutic potential of human mesenchymal stem cells producing IL-12 in a mouse xenograft model of renal cell carcinoma. Cancer letters. 2010; 290:157-166.

9. Zhang X, Zhang L, Xu W, Qian H, Ye S, Zhu W, Cao H, Yan Y, Li W, Wang M, Wang W, Zhang R. Experimental therapy for lung cancer: umbilical cord-derived mesenchymal stem cell-mediated interleukin-24 delivery. Current cancer drug targets. 2013; 13:92-102.

10. Bartosh TJ, Ylostalo JH, Mohammadipoor A, Bazhanov N, Coble K, Claypool K, Lee RH, Choi H, Prockop DJ. Aggregation of human mesenchymal stromal cells (MSCs) into 3D spheroids enhances their antiinflammatory properties. Proc Natl Acad Sci U S A. 2010; 107:13724-13729.

11. Heeschen C, Lehmann R, Honold J, Assmus B, Aicher A, Walter DH, Martin H, Zeiher AM, Dimmeler S. Profoundly reduced neovascularization capacity of bone marrow mononuclear cells derived from patients with chronic ischemic heart disease. Circulation. 2004; 109:1615-1622.

12. Hu GW, Li Q, Niu X, Hu B, Liu J, Zhou SM, Guo SC, Lang HL, Zhang CQ, Wang Y, Deng ZF. Exosomes secreted by human-induced pluripotent stem cell-derived mesenchymal stem cells attenuate limb ischemia by promoting angiogenesis in mice. Stem Cell Res Ther. 2015; 6:10.

13. Diederichs S, Tuan RS. Functional comparison of humaninduced pluripotent stem cell-derived mesenchymal cells and bone marrow-derived mesenchymal stromal cells from the same donor. Stem Cells Dev. 2014; 23:1594-1610.

14. Lian Q, Zhang Y, Zhang J, Zhang HK, Wu X, Lam FF, Kang S, Xia JC, Lai WH, Au KW, Chow YY, Siu CW, Lee $\mathrm{CN}$, Tse HF. Functional mesenchymal stem cells derived from human induced pluripotent stem cells attenuate limb ischemia in mice. Circulation. 2010; 121:1113-1123.

15. Sakai K, Ohta T, Minoshima S, Kudoh J, Wang Y, de Jong PJ, Shimizu N. Human ribosomal RNA gene cluster: identification of the proximal end containing a novel tandem repeat sequence. Genomics. 1995; 26:521-526.

16. Liu X, Liu M, Xue Z, Pan Q, Wu L, Long Z, Xia K, Liang D, Xia J. Non-viral ex vivo transduction of human hepatocyte cells to express factor VIII using a human ribosomal DNA-targeting vector. Journal of thrombosis and haemostasis. 2007; 5:347-351.

17. Hu Y, Liu X, Long P, Xiao D, Cun J, Li Z, Xue J, Wu Y, Luo S, Wu L, Liang D. Nonviral gene targeting at rDNA locus of human mesenchymal stem cells. BioMed research international. 2013; 2013:135189.

18. Liu X, Wu Y, Li Z, Yang J, Xue J, Hu Y, Feng M, Niu W, Yang Q, Lei M, Xia J, Wu L, Liang D. Targeting of the human coagulation factor IX gene at rDNA locus of human embryonic stem cells. PLoS One. 2012; 7:e37071.

19. Sauane M, Gopalkrishnan RV, Sarkar D, Su ZZ, Lebedeva IV, Dent P, Pestka S, Fisher PB. MDA-7/IL-24: novel cancer growth suppressing and apoptosis inducing cytokine. Cytokine \& growth factor reviews. 2003; 14:35-51.

20. Jiang $\mathrm{H}$, Lin JJ, Su ZZ, Goldstein NI, Fisher PB. Subtraction hybridization identifies a novel melanoma differentiation associated gene, mda-7, modulated during human melanoma differentiation, growth and progression. Oncogene. 1995; 11:2477-2486.

21. Wei N, Fan JK, Gu JF, Liu XY. Double-regulated oncolytic adenovirus-mediated interleukin-24 overexpression exhibits potent antitumor activity on gastric adenocarcinoma. Hum Gene Ther. 2010; 21:855-864.

22. Hamed HA, Yacoub A, Park MA, Eulitt PJ, Dash R, Sarkar D, Dmitriev IP, Lesniak MS, Shah K, Grant S, Curiel DT, Fisher PB, Dent P. Inhibition of multiple protective signaling pathways and Ad.5/3 delivery enhances mda-7/ IL-24 therapy of malignant glioma. Mol Ther. 2010; 18:1130-1142.

23. Eulitt PJ, Park MA, Hossein H, Cruikshanks N, Yang C, Dmitriev IP, Yacoub A, Curiel DT, Fisher PB, Dent P. Enhancing mda-7/IL-24 therapy in renal carcinoma cells by inhibiting multiple protective signaling pathways using sorafenib and by Ad.5/3 gene delivery. Cancer Biol Ther. 2010; 10:1290-1305.

24. Azab B, Dash R, Das SK, Bhutia SK, Shen XN, Quinn BA, Sarkar S, Wang XY, Hedvat M, Dmitriev IP, Curiel DT, Grant S, Dent P, et al. Enhanced delivery of mda-7/ IL-24 using a serotype chimeric adenovirus (Ad.5/3) in combination with the Apogossypol derivative BI-97C1 (Sabutoclax) improves therapeutic efficacy in low CAR colorectal cancer cells. J Cell Physiol. 2012; 227:2145-2153.

25. Li YJ, Liu G, Xia L, Xiao X, Liu JC, Menezes ME, Das SK, Emdad L, Sarkar D, Fisher PB, Archer MC, Zacksenhaus E, Ben-David Y. Suppression of Her2/Neu mammary tumor development in mda-7/IL-24 transgenic mice. Oncotarget. 2015; 6:36943-36954. doi: 10.18632/oncotarget.6046.

26. Sarkar S, Quinn BA, Shen XN, Dash R, Das SK, Emdad L, Klibanov AL, Wang XY, Pellecchia M, Sarkar D, Fisher PB. Therapy of prostate cancer using a novel cancer terminator virus and a small molecule $\mathrm{BH}-3$ mimetic. Oncotarget. 2015; 6:10712-10727. doi: 10.18632/oncotarget.3544.

27. Menezes ME, Shen XN, Das SK, Emdad L, Guo C, Yuan F, Li YJ, Archer MC, Zacksenhaus E, Windle JJ, Subler MA, Ben-David Y, Sarkar D, Wang XY, Fisher PB. MDA-7/ IL-24 functions as a tumor suppressor gene in vivo in transgenic mouse models of breast cancer. Oncotarget. 2015; 6:36928-36942. doi: 10.18632/oncotarget.6047.

28. Menezes ME, Bhatia S, Bhoopathi P, Das SK, Emdad L, Dasgupta S, Dent P, Wang XY, Sarkar D, Fisher PB. MDA-7/IL-24: multifunctional cancer killing cytokine. Adv Exp Med Biol. 2014; 818:127-153.

29. Lebedeva IV, Su ZZ, Chang Y, Kitada S, Reed JC, Fisher $\mathrm{PB}$. The cancer growth suppressing gene mda-7 induces apoptosis selectively in human melanoma cells. Oncogene. 2002; 21:708-718. 
30. Dash R, Bhutia SK, Azab B, Su ZZ, Quinn BA, Kegelmen TP, Das SK, Kim K, Lee SG, Park MA, Yacoub A, Rahmani M, Emdad L, et al. mda-7/IL-24: a unique member of the IL-10 gene family promoting cancer-targeted toxicity. Cytokine \& growth factor reviews. 2010; 21:381-391.

31. Wu Y, Gao T, Wang X, Hu Y, Hu X, Hu Z, Pang J, Li Z, Xue J, Feng M, Wu L, Liang D. TALE nickase mediates high efficient targeted transgene integration at the human multi-copy ribosomal DNA locus. Biochem Biophys Res Commun. 2014; 446:261-266.

32. Weir C, Morel-Kopp MC, Gill A, Tinworth K, Ladd L, Hunyor SN, Ward C. Mesenchymal stem cells: isolation, characterisation and in vivo fluorescent dye tracking. Heart, lung \& circulation. 2008; 17:395-403.

33. Zhou Y, Hu Q, Chen F, Zhang J, Guo J, Wang H, Gu J, Ma L, Ho G. Human umbilical cord matrix-derived stem cells exert trophic effects on beta-cell survival in diabetic rats and isolated islets. Disease models \& mechanisms. 2015; 8:1625-1633.

34. Ginn SL, Alexander IE, Edelstein ML, Abedi MR, Wixon J. Gene therapy clinical trials worldwide to 2012 - an update. J Gene Med. 2013; 15:65-77.

35. Miller JC, Tan S, Qiao G, Barlow KA, Wang J, Xia DF, Meng X, Paschon DE, Leung E, Hinkley SJ, Dulay GP, Hua KL, Ankoudinova I, Cost GJ, Urnov FD, Zhang HS, et al. A TALE nuclease architecture for efficient genome editing. Nature biotechnology. 2011; 29:143-148.

36. Karnoub AE, Dash AB, Vo AP, Sullivan A, Brooks MW, Bell GW, Richardson AL, Polyak K, Tubo R, Weinberg RA. Mesenchymal stem cells within tumour stroma promote breast cancer metastasis. Nature. 2007; 449:557-563.

37. Suzuki K, Sun R, Origuchi M, Kanehira M, Takahata T, Itoh J, Umezawa A, Kijima H, Fukuda S, Saijo Y. Mesenchymal stromal cells promote tumor growth through the enhancement of neovascularization. Molecular medicine. 2011; 17:579-587.

38. Sasportas LS, Kasmieh R, Wakimoto H, Hingtgen S, van de Water JA, Mohapatra G, Figueiredo JL, Martuza RL, Weissleder R, Shah K. Assessment of therapeutic efficacy and fate of engineered human mesenchymal stem cells for cancer therapy. Proc Natl Acad Sci U S A. 2009; 106:4822-4827.

39. Qiao L, Xu ZL, Zhao TJ, Ye LH, Zhang XD. Dkk-1 secreted by mesenchymal stem cells inhibits growth of breast cancer cells via depression of Wnt signalling. Cancer letters. 2008; 269:67-77.

40. Shou P, Chen Q, Jiang J, Xu C, Zhang J, Zheng C, Jiang M, Velletri T, Cao W, Huang Y, Yang Q, Han X, Zhang L, et al. Type I interferons exert anti-tumor effect via reversing immunosuppression mediated by mesenchymal stromal cells. Oncogene. 2016; 35:5953-5962.

41. Qiao L, Xu Z, Zhao T, Zhao Z, Shi M, Zhao RC, Ye L, Zhang $X$. Suppression of tumorigenesis by human mesenchymal stem cells in a hepatoma model. Cell research. 2008; 18:500-507.

42. Otsu K, Das S, Houser SD, Quadri SK, Bhattacharya S, Bhattacharya J. Concentration-dependent inhibition of angiogenesis by mesenchymal stem cells. Blood. 2009; 113:4197-4205.

43. Valero V, 3rd, Wingate $H$, Chada S, Liu Y, Palalon F, Mills G, Keyomarsi K, Hunt KK. MDA-7 results in downregulation of AKT concomitant with apoptosis and cell cycle arrest in breast cancer cells. Cancer gene therapy. 2011; 18:510-519.

44. Bhutia SK, Das SK, Azab B, Menezes ME, Dent P, Wang XY, Sarkar D, Fisher PB. Targeting breast cancer-initiating/ stem cells with melanoma differentiation-associated gene-7/ interleukin-24. International journal of cancer. 2013; 133:2726-2736.

45. Maestroni GJ, Hertens E, Galli P. Factor(s) from nonmacrophage bone marrow stromal cells inhibit Lewis lung carcinoma and B16 melanoma growth in mice. Cellular and molecular life sciences. 1999; 55:663-667.

46. Nakamura K, Ito Y, Kawano Y, Kurozumi K, Kobune M, Tsuda H, Bizen A, Honmou O, Niitsu Y, Hamada H. Antitumor effect of genetically engineered mesenchymal stem cells in a rat glioma model. Gene Ther. 2004; 11:1155-1164.

47. Sauane M, Su ZZ, Gupta P, Lebedeva IV, Dent P, Sarkar D, Fisher PB. Autocrine regulation of mda-7/IL-24 mediates cancer-specific apoptosis. Proc Natl Acad Sci U S A. 2008; 105:9763-9768.

48. Fisher PB. Is mda-7/IL-24 a "magic bullet" for cancer? Cancer research. 2005; 65:10128-10138.

49. Hingtgen S, Kasmieh R, Elbayly E, Nesterenko I, Figueiredo JL, Dash R, Sarkar D, Hall D, Kozakov D, Vajda $\mathrm{S}$, Fisher PB, Shah K. A first-generation multi-functional cytokine for simultaneous optical tracking and tumor therapy. PLoS One. 2012; 7:e40234.

50. Lebedeva IV, Su ZZ, Vozhilla N, Chatman L, Sarkar D, Dent P, Athar M, Fisher PB. Mechanism of in vitro pancreatic cancer cell growth inhibition by melanoma differentiation-associated gene-7/interleukin-24 and perillyl alcohol. Cancer research. 2008; 68:7439-7447.

51. Germano IM, Emdad L, Qadeer ZA, Binello E, Uzzaman M. Embryonic stem cell (ESC)-mediated transgene delivery induces growth suppression, apoptosis and radiosensitization, and overcomes temozolomide resistance in malignant gliomas. Cancer gene therapy. 2010; 17:664-674.

52. Huo W, Li ZM, Zhu XM, Bao YM, An LJ. MDA-7/IL-24 suppresses tumor adhesion and invasive potential in hepatocellular carcinoma cell lines. Oncology reports. 2013; 30:986-992.

53. Gopalan B, Shanker M, Chada S, Ramesh R. MDA-7/IL-24 suppresses human ovarian carcinoma growth in vitro and in vivo. Molecular cancer. 2007; 6:11. 
54. Beers J, Gulbranson DR, George N, Siniscalchi LI, Jones J, Thomson JA, Chen G. Passaging and colony expansion of human pluripotent stem cells by enzyme-free dissociation in chemically defined culture conditions. Nature protocols. 2012; 7:2029-2040.
55. Xue J, Liu X, He Q, Li Z, Hu Y, Gao T, Liang D, Yang J, Wu L, Long Z, Xia K, Xue Z, Pan Q, et al. In vitro efficacy of mda-7 gene for hepatocellular carcinoma gene therapy mediated by human ribosomal DNA targeting vector. Progress in Biochemistry and Biophysics. 2009; 36:1429-1435. 